\title{
MANFAAT EKSTRAK DANDELION DALAM MENCEGAH OSTEOPOROSIS
}

\author{
Danang Samudro Wicaksono, Rifadly Yusril Maulana \\ Fakultas Kedokteran, Universitas Lampung, Jl. Prof. Dr. Ir. Sumantri Brojonegoro No.1, Gedong \\ Meneng, Kec. Rajabasa, Kota Bandar Lampung, Lampung, Indonesia 35145 \\ *samudro.danang10@gmail.com (+6281271878294)
}

\begin{abstract}
ABSTRAK
Osteoporosis adalah penyakit tulang sistemik yang ditandai oleh penurunan densitas massa tulang sehingga tulang menjadi rapuh dan mudah patah. Karakteristik osteoporosis adalah ditandai dengan adanya penurunan kekuatan tulang dengan faktor resiko berupa usia, ras kaukasian, jenis kelamin wanita, defisiensi kalsium dan vitamin, aktifitas fisik, dan merokok. Dandelion mengandung berbagai vitamin, mineral, dan inulin yang baik untuk pencegahan terjadinya osteoporosis. Tujuan dari tinjauan pustaka ini adalah untuk melaporkan temuan ilmiah terbaru tentang peran kandungan Dandelion dalam mencegah osteoporosis dengan kandungannya yang dapat membantu proses penyeimbangan kebutuhan gizi dalam membentuk tulang. Metode yang digunakan dalam artikel berjenis tinjauan pusta ka ini adalah literature searching method melalui database NCBI dan Google Scholar. Tahun penerbitan sumber pustaka adalah dari tahun 1991 sampai tahun 2018 dengan 21 sumber pustaka dan 12 sumber yang dapat digunakan. Tema yang dikumpulkan terkait dengan kandungan Dandelion dalam mencegah osteoporosis. Hasil dari sintesis artikel yang telah ditemukan yaitu Dandelion bermanfaat dalam mencegah osteoporosis.
\end{abstract}

Kata kunci: dandelion, inulin, kalsium, osteoporosis

\section{THE BENEFIT OF DANDELION TO PREVENTS OSTEOPOROSIS}

\begin{abstract}
Osteoporosis is a systemic bone disease characterized by a decrease in bone mass density so that bones become brittle and break easily. The characteristics of osteoporosis are characterized by a decrease in bone strength with risk factors such as age, caucasian race, female sex, calcium and vitamin deficiency, physical activity, and smoking. Dandelion contains various vitamins, minerals, and inulin which are good for preventing osteoporosis. The purpose of this literature review is to report the latest scientific findings about the role of Dandelion content in preventing osteoporosis with its contents which can help the process of balancing nutritional needs in forming bone. The method used in this type of literature review article is the literature searching method through the NCBI and Google Scholar databases. The year of publication of library resources is from 1991 to 2018 with 21 library sources and 12 usable sources. The theme collected is related to the content of Dandelion in preventing osteoporosis. The results of the synthesis of articles that have been found that Dandelion is useful in preventing osteoporosis.
\end{abstract}

Keywords: calcium, dandelion, inulin, osteoporosis

\section{PENDAHULUAN}

Osteoporosis adalah penyakit tulang sistemik yang ditandai oleh penurunan densitas massa tulang sehingga tulang menjadi rapuh dan mudah patah
(Sudoyo et al., 2009). Menurut, konferensi pengembangan lembaga Konsensus Kesehatan Nasional, Osteoporosis adalah kelainan tulang yang ditandai dengan berkurangnya 
kekuatan tulang yang menghasilkan peningkatan risiko patah tulang $(\mathrm{NIH}$, 2001).

Faktor resiko terjadinya osteoporosis yaitu usia, setiap peningkatan usia sepuluh tahun maka resiko meningkat 1,4 hingga 1,8 kali. Secara genetik, kaum kaukasian dan oriental lebih beresiko mengalami osteoporosis dibandingkan kulit hitam dan polinesia. Osteoporosis juga lebih banyak dialami perempuan dibandingkan laki-laki. Pada faktor lingkungan, hal yang mempengaruhi yaitu defisiensi kalsium, kurangnya aktivitas fisik, merokok, alkohol, obat-obatan (kortikosteroid, antikonvulsan, heparin, siklosporin), dan pada resiko jatuh yang meningkat (gangguan penglihatan, gangguan keseimbangan). Defisiensi estrogen dan androgen, serta penyakit kronik juga merupakan faktor resiko terjadinya osteoporosis (Sudoyo et al., 2009).

Di dunia, menurut WHO, terdapat sekitar 200 juta orang menderita osteoporosis. Sementara di Amerika terdapat 20-25 juta penduduk mengalami osteoporosis dengan 50 persen berusia 75-80 tahun. Menurut International Osteoporosis Foundation (IOF), satu dari empat perempuan dengan rentang umur 50-80 tahun di Indonesia rentan mengalami osteoporosis. Perbandingan terjadinya osteoporosis antara perempuan dan lakilaki di Indonesia yaitu 4;1. Pada wanita sendiri lebih sering terjadi pada wanita paska menopause. Perhimpunan osteoporosis Indonesia tahun 2007 melaporkan penderita osteoporosis pada penduduk di atas 5 tahun yaitu pada perempua 32,3 persen dan pada laki-laki 28,8 persen (Info Datin, 2015).

Karakteristik osteoporosis adalah ditandai dengan adanya penurunan kekuatan tulang (Bone strength). Kekuatan tulang ini adalah hasil integrasi antara volume mineralisasi, arsitektur tulang, bone turn over, dan akumulasi kerusakan tulang. Osteoporosis identik dengan kehilangan massa tulang, yaitu kelainan tulang yang merujuk pada kelainan kekuatan tulang. Apabila kekuatan tulang ini menurun maka hal ini dapat menjadi faktor predisposisi terjadinya fraktur (Drake et al., 2005).

Meskipun tatalaksana farmakologis paling sering dilakukan, agar pengobatan osteoporosis optimal, tatalaksana nonfarmakologis juga penting untuk mencegah osteoporosis dan membatasi risiko patah tulang.

Adapun salah satu bahan alam yang dapat menjadi alternatif dalam mencegah osteoporosis yaitu Dandelion. Dandelion atau Jombang, merupakan keluarga besar Asteraceae atau Compositae dengan nama latin Taraxacum officinale. Dandelion juga kaya akan vitamin (A, C, D, E, dan B), inositol, lesitin, dan mineral seperti zat besi, magnesium, natrium, kalsium, silikon, tembaga, fosfor, seng, dan mangan (Ata et al., 2011). Dandelion mengandung inulin dan fruktooligosakarida dapat meningkatkan penyerapan kalsium, menekan resorpsi tulang, dan meningkatkan pertambahan selama pertumbuhan dan menghambat resorpsi tulang di kemudian hari (Abrams et al, 2005). Untuk itu tujuan penulisan tinjauan pustaka ini penting untuk mengetahui kandungan dan mannfaat yang ada pada tumbuhan Dandelion terhadap pencegahan osteoporosis.

\section{METODE}

Metode yang digunakan adalah literature searching. Sumber pustaka 
yang digunakan dalam artikel ini berjumlah 21 pustaka dan 12 jurnal yang dipakai dalam review manfaat Dandelion terhadap osteoporosis, baik yang berasal dari buku, jurnal nasional atau internasional, maupun website. Penelusuran sumber pustaka dalam artikel ini melalui database NCBI dan Google Scholar dengan kata kunci Phyllantus acidus, Antiinflammation, Asthma. Pemilihan artikel sumber pustaka dilakukan dengan melakukan peninjauan pada judul dan abstrak yaitu membahas tentang potensi buah cermai dalam mengatasi asma. Tahun penerbitan sumber pustaka dalam penulisan artikel ini adalah 1991 hingga tahun 2018.

\section{HASIL}

Dandelion (Taraxacum officinale) merupakan tumbuhan dengan berbagai macam kandungan seperti inulin yang dapat meningkatkan penyerapan kalsium, vitamin yang bermanfaat untuk pembentukan tulang seperti $\mathrm{A}, \mathrm{C}, \mathrm{D}$, dan $\mathrm{K}$, serta mineral penting lain seperti fosfor, magnesium, zat besi, seng dan lainnya yang dapat menjadi penyeimbangan kebutuhan gizi dalam membentuk tulang. Atas dasar hal ini kandungan ekstrak Dandelion dapat bermanfaat dalam mencegah terjadinya osteoporosis (Ata et al., 2011).

Pada penelitian pemisahan dan kuantifikasi inulin dari Artichoke dan Dandelion, ditemukan bahwa keduanya memiliki kandungan inulin dengan Dandelion memiliki dp20 rata-rata 25 $\mathrm{nC}$, dp30 rata-rata $18 \mathrm{nC}$, dan dp40 ratarata $15 \mathrm{nC}$ (Schutx et al., 2006). Inulin dengan $d p>23$ memiliki efek paling signifikan pada bioavailabilitas kalsium ketika diberikan pada tikus (Kruger et al. 2003).
Dandelion adalah sumber potasium yang signifikan, serta vitamin dan mineral lainnya.12 Kadar potasium yang dilaporkan berkisar antara 23,3/g mg hingga $59,9 \mathrm{mg} / \mathrm{g}$ dengan angka median $42,5 \mathrm{mg} / \mathrm{g}$ dan $45,1 \mathrm{mg} / \mathrm{g}$ daun kering, serta mengandung magnesium sekitar $2.5 \mathrm{mg} / \mathrm{g}$ (Bevin et al., 2009).

Pada setiap 100 gram tepung Dandelion mengandung $695.00 \pm 4.00$ kalsium, $700.00 \pm 3.00$ fosfor, $2520.00 \pm 4.00$ potasium, $470.00 \pm 2.00$ magnesium, $13.80 \pm 0.20$ beta karoten atau vitamin A, $53.00 \pm 0.10$ asam asorbat atau vitamin C (Escudero et al., 2003). Kandungan-kandungan tersebut memiliki manfaat terhadap pembentukan dan densitas tulang.

\section{PEMBAHASAN}

Osteoporosis merupakan gabungan kondisi tulang yang menjadi tipis, rapuh, keropos, serta memiliki kecenderungan patah diakibatkan ole massa tulang yang berkurang dalam waktu yang lama. Secara statistik, osteoporosis didefinisikan sebagai keadaan di mana Bone Mineral Density (BMD) berada di bawah nilai rujukan menurut umur atau standar deviasi (Depkes RI, 2002).

Pengukuran Bone Mineral Density (BMD) dan Dual Energy X-ray Absorptiometry (DXA) merupakan standar emas dalam mendiagnosis osteoporosis. DXA menggunakan 2 energi radiasi sinar- $\mathrm{X}$ sehingga pengaruh jaringan lunak dapat dihilangkan dan dapat mengukur kepadatan tulangtulang sentral seperti tulang belakang (L1-L4) dan femur proksimal, tulang-tulang perifer seperti lengan bawah dan juga dapat mengukur total body BMD. Pengukuran BMD yang rutin dilakukan adalah di tulang belakang dan femur proksimal (Punda 
dan Grazio, 2014). Nilai T-score $<-2,5$ digolongkan sebagai osteoporosis. Nilai T-score di bawah -1,0 adalah osteopenia atau massa tulang yang rendah. Nilai $\mathrm{T}$ score di antara -1 sampai +1 adalah BMD (Bone Mineral Density) normal (Tandra, 2009).

Klasifikasi osteoporosis dibagi menjadi 3, yaitu; Osteoporosis primer yang dibagi menjadi dua, osteoporosis primer tipe 1 yaitu kehilangan massa tulang yang terjadi karena proses penuaan yaitu akibat kekurangan estrogen pada wanita paska menopause dan kekurangan testosteron yakni androgen pada pria. Pada osteoporosis primer tipe 2 disebut osteoporosis senil yang dapat terjadi pada pria dan wanita di atas usia 75 tahun. Selanjutnya yaitu Osteoporosis sekunder, disebabkan oleh adanya penyakit yang mendasari dan pengaruh obat-obatan yang mengakibatkan adanya penurunan densitas tulang yang parah. Terakhir, osteoporosis idiopatik, tidak diketahui penyebabnya, biasa muncul pada anakanak, remaja, dan dewasa muda (Info Datin, 2015).

Pada akhir percepatan pertumbuhan pubertas (titik waktu di mana massa tulang puncak tercapai) hingga permulaan usia paruh baya, baik pria maupun wanita mempertahankan kerangka mereka tanpa kehilangan tulang yang substansial atau perubahan mikroarsitektur kerangka. Remodelling tulang sangat aktif selama periode dewasa ini, yaitu resorpsi tulang seimbang dengan pembentukan tulang, menghasilkan stabilitas massa tulang dan pemeliharaan integritas kerangka. Penurunan besar volume densitas massa tulang dimulai sejak dekade ketiga pada pria dan wanita, terutama terdiri dari tulang trabekuler, $45 \%$ pada pria dan $55 \%$ pada wanita (Riggs et al., 2004).
Pria tidak mengalami menopause, sehingga pria tidak mengalami kehilangan tulang trabekuler akselerasi dini yang terjadi pada wanita sehingga kehilangan tulang relatif lebih sedikit daripada wanita (Khosla dan Riggs, 2005).

Pada osteoporosis primer tipe 1, reabsorbsi tulang meningkat terutama pada dekade awal paska menopause, penurunan densitas terutama pada tulang trabekular karena memiliki permukaan yang luas. Penurunan kadar esterogen akan meningkatkan produksi berbagai sitokin seperti IL-6, IL-1, dan TNF-alfa yang berperann dalam peningkatan aktifitas osteoklas. Menopause juga menurunkan absorpsi kalsium di usus dan meningkatkan ekskresi kalsium di ginjal. Akibatnya hormon paratiroid meningkat sebagai umpan balik penurunan kalsium (Sudoyo et al., 2009).

Pada osteoporosis primer tipe 2, terjadi ketidakseimbangan remodelling tulang pada usia lanjut, dimana reabsorbi tulang meningkat sedangkan formasi tulang menurun. Hal ini menyebabkan terjadinya kehilangan massa tulang, perubahan mikroarsitektur tulang, dan meningkatnya resiko patah tulang. Pada orang lanjut usia juga didapatkan defisiensi kalsium dan vitamin D yang menyebabkan hiperparatiroidisme sekunder yang persisten sehingga reabsorbsi tulang meningkat. Selain itu juga disebabkan oleh penurunan hormon pertumbuhan dan IGF-1 sehingga terjadi penurunan fungsi osteoblas (Drake et al., 2015).

Meskipun pengobatan paling sering dikaitkan dengan pendekatan farmakologis, untuk pengobatan osteoporosis yang optimal, pendekatan nonfarmakologis juga penting untuk 
membatasi risiko patah tulang. Intervensi nonfarmakologis termasuk membatasi risiko jatuh; menggunakan teknik yang tepat saat mengangkat; mempertahankan asupan kalsium, vitamin $\mathrm{D}$, dan protein yang memadai; melakukan aktivitas fisik dan latihan beban yang memadai untuk menjaga atau meningkatkan keseimbangan dan postur; dan membuat perubahan gaya hidup yang tepat, seperti penghentian merokok dan konsumsi alkohol. (Kristie et al., 2018).

Dandelion atau Jombang, merupakan keluarga besar Asteraceae atau Compositae dengan nama latin Taraxacum officinale. Umumnya Dandelion tumbuh liar di lereng gunung, tanggul, lapangan rumput, dan daerah berhawa sejuk. Tinggi mencapai 10-25 cm, daun tunggal berbentuk lancet, ujung runcing, pangkal menjepit menyerupai tangkai daun, tepi bergerigi, panjang daun 6-15 cm dengan lebar 2-5 $\mathrm{cm}$, berwarna hijau dilapisi bulu halus berwarna putih. Buahnya berbentuk tabung berwarna putih. Akarnya panjang, tunggal atau bercabang. (Dalimarta, 2008).

Akar dandelion mengandung karbohidrat (misalnya Inulin), karotenoid (mis. Lutein), asam lemak (misalnya Asam miristat), mineral, gula (misalnya glukosa, fruktosa, dan sukrosa), vitamin kolin, lendir, dan pektin. Hingga $45 \%$ dari akar terdiri dari inulin, karbohidrat kompleks (fructo-oligosaccharides) dengan banyak efek menguntungkan seperti eliminasi patogen di saluran pencernaan, dan represi obesitas, kanker, dan osteoporosis (Roberfroid, 1999).

Dandelion juga kaya akan vitamin (A, C, D, E, dan B), inositol, lesitin, dan mineral seperti zat besi, magnesium, natrium, kalsium, silikon, tembaga, fosfor, seng, dan mangan (Ata et al., 2011). Aliran beberapa ion ini, mis. ion kalsium dalam sel beta, dapat membantu merangsang eksositosis insulin. Di antara sayuran, dandelion adalah salah satu sumber terkaya betakaroten $(11.000 \mu \mathrm{g} / 100 \mathrm{~g}$ daun, sama seperti pada wortel), dari mana vitamin A berasal (Mir et al., 2015).

Dandelion mengandung inulin, karbohidrat khas Compositae. Inulin adalah campuran polydisperse dari oligomer dan polimer, di mana unit fruktosa dihubungkan oleh ikatan $\beta-2,1$. Seperti halnya polifenol, inulin memiliki sejumlah sifat fisiologis yang menarik. Kaitan $\beta-2,1$ mencegah inulin dicerna seperti karbohidrat biasa dan bertanggung jawab atas penurunan nilai kalori dan efek serat makanan (Roberfroid, 1999). Inulin dan fructooligosakarida juga telah terbukti dapat meningkatkan penyerapan kalsium, menekan resorpsi tulang, dan meningkatkan pertambahan selama pertumbuhan dan menghambat resorpsi tulang di kemudian hari (Abrams et al, 2005).

Selain itu Dandelion juga kaya akan sumber mineral seperti potasium, zat besi, magnesium, seng, kalsium, boron, dan silikon (Queralt at el., 2005). Selama masa pertumbuhan, kecukupan asupan diet kalsium penting dipertimbangkan untuk tambahan kekuatan dan kesehatan tulang (Heaney et al., 2000). menyatakan anak-anak untuk mencapai puncak massa tulang yang baik secara genetik, maka menu yang disajikan kepada anak harus mencukupi kebutuhan kalsium pada tulang. Pertumbuhan dari puncak massa tulang yang baik semasa muda adalah 
penting untuk mencegah osteoporosis pada usia lanjut (Loro 2000).

Menurut penelitian dalam membentuk tulang yang sehat tidak hanya dengan mengkonsumsi cukup kalsium namun dibutuhkan pula zat-zat lainnya untuk meningkatkan proses distribusi mineral dan menyeimbangkan kebutuhan gizi. Zat-zat gizi tersebut terdiri dari vitamin seperti vitamin A, D, C, dan $\mathrm{K}$, serta mineral seperti magnesium, fluor, seng, tembaga, boron, mangan, fosfor, dan kalium. (Serfontain, 2005).

Vitamin A yang dikandung dalam Dandelion, berperan penting dalam proses remodelling tulang hal ini dikarenakan vitamin A (asam retinoat) merupakan reseptor dari osteoblas dan osteoklas. Kekurangan vitamin A dapat menyebabkan terjadinya perubahan bentuk tulang. Asupan vitamin A yang sesuai dengan angka kecukupan gizi (AKG) yaitu sebesar $500 \mu \mathrm{g}$ RE dapat menjaga dan memelihara puncak kepadatan tulang Promislow et al., 2002. Asupan vitamin A yang berlebihan juga tidak baik karena berhubungan dengan penurunan BMD dan peningkatan risiko patah tulang paha. (Sankaran, 2000).

Vitamin $\mathrm{C}$ juga mampu merangsang aktivitas alkalin fosfat sebagai penentu pembentukan osteoblas. Vitamin $\mathrm{C}$ merupakan komponen organik pada tulang untuk perubahan-perubahan sel dan pembentukan matriks tulang baru. Vitamin C tidak bekerja sendiri tetapi dibantu oleh vitamin $\mathrm{D}$ dan $\mathrm{K}$ (Ramayulis et al., 2011).

Seng dibutuhkan untuk aktivitas osteoblastik, sintesis kolagen, dan aktivitas alkalin fosfatase. Sebagai komponen dari sistem enzim, seng berperan dalam pergantian matriks tulang (Wolf et al., 2005).

Fosfor merupakan salah satu elemen pembentukan tulang karena dibutuhkan dalam proses mineralisasi tulang. Asupan fosfor memiliki peranan yang cukup penting dalam pembentukan tulang pada masa pertumbuhan. Kadar fosfat serum yang rendah akan membatasi pembentukan tulang dan proses mineralisasi tulang (Palacios, 2006).

\section{SIMPULAN}

Dandelion bermanfaat dalam mencegah osteoporosis.

\section{DAFTAR PUSTAKA}

NIH. (2011). Consensus Development Panel on Osteoporosis Prevention, Diagnosis, and Therapy. Osteoporosis prevention, diagnosis, and therapy. JAMA. 2001;285: 785-795. DOI: $\underline{10.1001 / j a m a .285 .6 .785}$

Ata, S., Farooq, F., Javed, S. Elemental profile of 24 common medicinal plants of Pakistan and its direct link with traditional uses. J Med Plants Res. ;5(26):6164-6168. pmc5553762

Mir, M.A., Sawhney, S.S., Jassal, M.M. (2015). In-vitro antidiabetic studies of various extracts of Taraxacum officinale. Pharma Innov. ;4(1):61-66.

Promislow, J. H., Goadman, G. D., Slymen, D. J., Elizabeth, B. C. (2002). Retinol intake and bone mineral density in the elderly; the Rancho Bernardo study. J Bone Mineral Res; 17(8): 1349-58. DOI:

$\underline{\text { 10.1359/jbmr.2002.17.8.1349 }}$ 
Sankaran, B. (2000). Osteoporosis; clinical, radiological, histological, assessment and an experimental study. New Delhi, India: World Health Organisation.

Kristie, N. T., Janette, D. L., Chew King Victoria Wan, Madison C, et al (2018). Osteoporosis: A Review of Treatment Options. Pharmacy and Therapeutic Journal. Feb; 43(2): 92-104.

Ramayulis, R., Pramantara D. I., Pangastuti, R. (2011). Asupan vitamin, mineral, rasio asupan kalsium dan fosfor dan hubungannya dengan kepadatan mineral tulang kalkaneus wanita. Jurnal Gizi Klinik Indonesia. Vol.7 No.3 p115-112

Serfontein, W. J. (2005). Osteoporosis : new perspectives. The South African Journal of Natural Medicine Available from; http:// www.naturalmedicine.co.za/sajnm _main/article.

Abrams, S. A., Griffin, I. J., Hawthorne, K. M., et al. (2005) A combination of prebiotic short and long - chain inulin type fructans enhances calcium absorption and bone mineralization in young adolescents. Am J Clin Nutr 85, $471-476$.

Info Datin. (2015). Data \& Kondisi Penyakit Osteoporosis di Indonesia. www.depkes.go.id/resources/dow nload/general/Hasil\%20Riskesdas \%20213.pdf

Sudoyo, A. W., Setyohadi, B., Alwi, I. dkk. (2009). Buku Ajar Ilmu
Penyakit Dalam. Edisi V. Jakarta: Interna Publishing Pusat Penerbitan Ilmu Penyakit Dalam. ; 2773-2779

Roberfroid, M. B. (1999). Caloric value of inulin and oligofructose. Journal of Nutrition; 129: 1436S.

Drake, M. T., Clarke, B. L., \& Lewiecki, E. M. (2015). The Pathophysiology and Treatment of Osteoporosis. Clinical Therapeutics, 37(8), 1837-1850. DOI:

$\underline{10.1016 / j . c l i n t h e r a .2015 .06 .006}$

Wolf R. L., Cauley J. A, Pettinger M, Jackson R, Lacroix Wolf A, Leboff M. S, Lewis C. E, Nevitt M. C, Simon JA, Stone KL, Wactawski-Wende J. (2005). Lack of a relation between vitamin and mineral antioxidants and bone mineral density : results from the women's health initiative. Am J Clin Nutr; 82(3): 581-8.

Riggs BL, Melton LJ 3rd, Robb RA, et al. (2004). Populationbased study of age and sex differences in bone volumetric density, size, geometry, and structure at different skeletal sites. J Bone Miner Res.;19:1945-1954. DOI: 10.1359/JBMR.040916

Khosla, S, Riggs, B. L. (2005). Pathophysiology of age-related bone loss and osteoporosis. Endocrinol Metab Clin North Am.;34:1015-1030. DOI $\underline{\text { 10.1016/j.ecl.2005.07.009 }}$

Dalimartha, S. (2008). Atlas Tumbuhan Obat Indonesia Jilid 4. Puspa Swara 
Depkes. R.I. (2002). Standart Osteoporosis. Jakarta; Litbangkes

Tandra, H. (2009). Osteoporosis Mengenal, Mengatasi, dan Mencegah Tulang Keropos. Jakarta: Gramedia Pustaka Utama.

Punda, M., Grazio, S. (2014). Bone densitometry, the gold standard for diagnosis of osteoporosis. Journal of Reumatizam 61(2):704. PMID: 25427398

Kruger, M. C., Brown, K.E., Collett, G, Layton, L and Schollum, L.M. (2003). The effect of fructooligosaccharides with various degrees of polymerization on calcium bioavailability in the growing rat. Experimental Biology and Medicine; 228: 683

Schütz, K., Muks, E., Carle, R., \& Schieber, A. (2006). Separation and quantification of inulin in selected artichoke (Cynara scolymus L.) cultivars and dandelion (Taraxacum officinale WEB. ex WIGG.) roots by high- performance anion exchange chromatography with pulsed amperometric detection. Biomedical Chromatography, 20(12), 1295-1303.

Escudero, N. L., De Arellano, M. L., Fernández, S., Albarracín, G., \& Mucciarelli, S. (2003). Taraxacum officinale as a food source. Plant Foods for Human Nutrition, 58(3), 1-10.

Bevin A.C., Richard S. C., Kevin S. (2009). The diuretic effect in human subject of an extract of taraxacum officinale folium over a single day. Journal Atern Complement Med. 15(8):929-34

Palacios, C. (2006). The role of nutrients in bone health, from $\mathrm{A}$ to Z. Crit Rev Food Sci Nutr; 46(8):621- 